\title{
NOTAS PARA ENTENDER \\ A REALIDADE MEXICANA
}

\author{
VÍCTOR MANUEl DURAND PONTE \\ TRADUÇÃO DE LUCIANA PUDENZI
}

\section{RESUMO}

A combinação de decisões equivocadas de política econômica, fragilidade do Estado de direito e rigidez conservadora do sistema político conduziram o México ao presente estado de crise social aguda. A violência brutal desencadeada pelo crime organizado trouxe à luz essas profundas deficiências.

PALAVRAS-CHAVE: Crise social; migração internacional; economia mexicana; sistema político mexicano.

\section{ABSTRACT}

Bad economic policy decisions, weak rule of law and the conservative rigidity of Mexico's political system have led the country to its present state of deep social crisis. The brutal violence of the drug cartels has made explicit the failures of the Mexican state.

KEYWORDS: Social crisis; international migration; Mexican economy; Mexican political system.

[1] Nos últimos quatro anos, houve 28 mil assassinatos atribuíveis ao crime organizado. El Universal, 3 ago. 2010.
A imagem que os meios de comunicação de massa apresentam do México, para o exterior e para o interior do país, é a de uma sociedade em crise e em franco processo de deterioração.

A crise social tem como indicador mais perceptível e divulgado a violência do crime organizado, seja internamente (luta entre diferentes cartéis ou organizações), seja nos confrontos com as instituições do Estado (forças armadas e polícia), seja, ainda, na violência contra a sociedade, que acomete especialmente jornalistas e vítimas inocentes dos conflitos armados. A violência cada vez mais intensa ${ }^{1}$, brutal e sangrenta gera a impressão de que o Estado é incapaz de conter e punir os culpados. Afirma-se, inclusive, que o Estado mexicano seria um Estadofalido. 
À imagem da violência acrescenta-se ainda outro elemento, também muito noticiado, menos conjuntural e mais permanente: a migração ilegal de mexicanos para os Estados Unidos. Calcula-se que cerca de 400 mil migrantes cruzam a fronteira anualmente, em busca da oportunidade de trabalho que não encontram no México ou para reunir-se com seus familiares já radicados nos Estados Unidos. Sem dúvida, isso é um indicador da falta de dinamismo do mercado de trabalho interno, que encontra sua solução parcial no trânsito migratório. Sem essa válvula de escape, a miséria, o desemprego e a informalidade no México seriam muito maiores, e os conflitos sociais a eles associados ainda mais intensos ${ }^{2}$.

Estes dois temas também constituem os pontos críticos das relações entre o México e os Estados Unidos. Felizmente, há um espírito de cooperação entre os governos, mas a questão não deixa de ser um fator de tensão política e diplomática, especialmente com os setores conservadores do país do norte.

A crise possui também uma expressão econômica, talvez menos divulgada, mas igualmente grave. A última demonstração disso foi a recessão enfrentada pela economia mexicana em 2009 , a maior entre os países da América Latina (com queda de 6,5\% no PIB). No entanto, o problema é maior, como demonstra o fraco crescimento econômico dos últimos trinta anos (média anual de $2 \%$ de crescimento do PIB)3. Paradoxalmente, a crise contrasta com a estabilidade macroeconômica que o país manteve na última década.

Por fim, outra imagem da realidade mexicana que preocupa os observadores é o espectro de uma espécie de fracasso do regime democrático, fracasso que se expressa no "inevitável" retorno do Partido Revolucionário Institucional (PRI) à presidência4 . Não há como deixar de pensar que isso significa a volta do velho autoritarismo, sobretudo porque, nos últimos anos, o PRI não se reformulou, persistindo com os mesmos dirigentes do período autoritário, com suas velhas ideias e hábitos.

Como explicar essa situação? Como entender que, embora outros países da região tenham desenvolvimento econômico e social muito significativos (como o Brasil e o Chile, mas também o Peru ou a Colômbia), o México esteja vivenciando, aparentemente, uma dinâmica muito diferente? Como explicar a fragilidade da democracia mexicana?

Neste breve ensaio, pretendo apenas assinalar alguns elementos que possam ajudar a compreensão, de maneira geral, do que está ocorrendo.

Para se compreender a realidade mexicana, é necessário levar em consideração dois grandes processos. Em primeiro lugar, a mudança na economia mexicana, que passou do modelo de desenvolvimento voltado para dentro (por meio da substituição de importações) a uma economia mundial aberta, com ênfase no mercado mundial. O segun-
[2] Estima-se que, em 2010, trabalhavam nos Estados Unidos 8,6 milhões de mexicanos. Este País, $\mathrm{n}^{\circ} 230$, 2010, Foro Indicadores, Escenario Macroeconómico, p. 46.

[3] A falta de dinamismo se expressa na queda do PIB por habitante nos anos recentes: de 141,1 dólares por habitante em 2007, passou a 135,4 em 2010. Este País, op cit.

[4] Esta imagem se fortaleceu após os triunfos do PRI nas eleições de 2009, nas quais conquistou maioria na Câmara dos Deputados e quase todos postos de governo que estavam em disputa, inclusive em alguns redutos do Partido Ação Nacional (PAN)e do Partido da Revolução Democrática (PRD). 
[5] Nos últimos quatro anos, foram apreendidas 84 mil armas do crime organizado.Reforma, 4 ago.2010, p.6.

[6] "Combatir el robo en Pemex llevará tiempo: Kessel". El Universal, 3 ago. 2010 . do processo são as transformações do sistema político, a crise do velho sistema autoritário centrado no presidencialismo, no nacionalismo revolucionário, e a criação de uma democracia eleitoral, com importantes modificações nas instituições políticas. Estes processos, que constituíram dois círculos viciosos, dificultam a solução da violência gerada pelo crime organizado e pelas migrações ilegais, assim como por toda a dinâmica do país.

Parto da hipótese de que os processos se deram por decisões governamentais que geraram verdadeiros círculos viciosos e introduziram a sociedade mexicana em um movimento de franca decadência. Isso implica que havia alternativas, mediante outras decisões; não houve, nem há, nada predeterminado.

Na próxima seção, apresentarei uma descrição da violência associada ao crime organizado e recordarei os fatores básicos do fenômeno migratório. Em seguida, abordarei o processo que desembocou no círculo vicioso da economia mexicana. Prosseguirei tratando das mudanças no sistema político e seu desdobramento na frágil democracia eleitoral. Por fim, algumas conclusões.

\section{A CRISE SOCIAL}

A atividade mais divulgada do crime organizado é o narcotráfico, mas não é a única - a ele, unem-se o tráfico de armas 5 e o tráfico de pessoas, tanto o relativo à migração para os Estados Unidos, como o tráfico ligado à prostituição nacional e internacional.A isso somam-se, ainda, o sequestro de pessoas para a exigência de resgates, o roubo de veículos e sua venda, inclusive em solo estrangeiro, o roubo em grande escala de combustíveis da empresa Pemex ${ }^{6}$ etc.

No caso do narcotráfico, seu início remonta aos anos da Segunda Guerra Mundial, quando se cultivou maconha no estado de Sinaloa (sede do cartel mais poderoso) para consumo do exército norte-americano em combate. A presença dos grupos que cultivavam e comercializavam as drogas não se interrompeu; pelo contrário, tornou-se cada vez mais complexa à medida que o consumo na sociedade norte-americana aumentou e que o cultivo em outros países da América do Sul requeria, para que a droga chegasse aos Estados Unidos, a intermediação de organizações mexicanas. Assim, os cartéis da droga fortaleceram-se e internacionalizaram-se, enquanto os volumes de drogas e de dinheiro cresceram exponencialmente.

Durante muitos anos, as organizações criminosas mantiveram-se na obscuridade - embora se soubesse de sua existência e de suas relações com os governos locais e até com o governo nacional. Seu aparecimento no espaço público na última década deveu-se a muitos fatores, mas cabe assinalar os seguintes como os mais relevantes:(1) as organi- 
zações criminosas7 tinham territórios bem definidos e havia um acordo de não interferir nas áreas controladas por outro cartel. Esse acordo foi rompido quando certas rotas de tráfego foram fechadas por intervenção do Estado, obrigando as organizações a entrar em territórios já ocupados. Em alguns casos houve alianças, em outros, guerra. (2) $\mathrm{O}$ consumo de narcóticos no país aumentou, formando-se um mercado interno que era abastecido por intrincadas redes de narcotraficantes até a chegada ao consumidor final. Esses mercados também passaram a ser áreas de disputa por parte das organizações. (3) A cumplicidade entre as organizações e os governantes, a polícia e o poder Judiciário foram crescendo e ameaçando a autonomia do Estado, em especial em alguns estados da República e em determinados municípios em que o controle do crime organizado era intolerável. As disputas entre os cartéis envolviam funcionários do governo, dividindo-os e enfrentando-os. No final do século passado e nos primeiros anos do atual, a presença e a atividade do narcotráfico e das organizações criminosas tornou-se inaceitável para o governo federal.

Em consequência disso, o governo do presidente Felipe Calderón (2006-2012) declarou guerra ao crime organizado, e, com isso, a violência entre os cartéis e entre estes e as forças do Estado aumentou. A partir dessa decisão, iniciou-se um círculo perverso envolvendo ataques mais intensos do governo contra os cartéis, com confiscos de drogas e com líderes de al to e médio escalão sendo afetados e mortos, gerando intensificação da violência, maior divisão dos cartéis, expansão territorial, mais investidas por parte do governo etc.

Segundo interpretações oficiais, o ataque às organizações iniciado neste mandato presidencial acarretou o enfraquecimento de alguns cartéis; em certos locais, abriu espaço para que facções internas lutassem abertamente pelo controle da organização, assim como outros cartéis tentaram, com êxito variado, aumentar seu controle sobre as zonas enfraquecidas. A luta tornou-se encarniçada, e a violência, cada vez mais brutal: corpos com terríveis marcas de tortura, cadáveres esquartejados ou pendurados em pontes, cabeças degoladas e deixadas em locais estratégicos para serem vistas e servir de exemplo e aviso aos rivais. Recentemente, carros-bomba foram explodidos, dando início a táticas terroristas.

A ação do crime organizado vai-se ampliando diante da fragilidade das instituições responsáveis pela justiça (a probabilidade de que um delinquente seja apanhadoé muito baixa), ao que se acrescentam a impunidade, a corrupção e a incompetência das polícias, especialmente das estaduais e municipais.

Os confrontos com as forças federais em zonas urbanas aumentam o número de vítimas inocentes, de civis atingidos por disparos de ambas as partes ${ }^{8}$. Também aumentaram as denúncias de maus-tratos
[7] Os cartéis mais importantes são: Sinaloa, Golfo,Juárez, Zetas, Tijuana, Pacífico Sur, La Barbi e Milenio.
[8] Segundo as cifras oficiais, nos últimos quatro anos houve em média um enfrentamento por dia entre organizações do crime organizado e forças federais em espaços públicos, ruas ou estradas. Reforma, 4 ago. 2010. 
[9] Como é óbvio, parte dessas denúncias é realizada pelas organizações criminosas, dificultando o papel da justiça.

[10] Estudos mostram que a violência no México, medida em termos de assassinatos por cada $100 \mathrm{mil}$ habitantes, está diminuindo, e que a violência atribuída ao crime organizado cresce em lugares e regiões específicos. Ver Gonzalvo, Fernando Escalante e Guerrero, Eduardo. "La violencia 1990-2009". Nexos, n ${ }^{\circ} 381$, 2009, pp. 25-42.
[11] Ogasto com segurança por parte do governo federal aumentou em $25 \%$ ao ano na última década; em 2009 , elevou-se a 4,3 bilhões de dólares. ou abusos, incluindo crimes cometidos por membros das forças armadas, provocando enfrentamentos com as instituições envolvidas com a defesa dos direitos humanos, que questionam o foro militar para o julgamento dos delitos cometidos por seus membros?.

Nesse processo, os cartéis conquistam maior visibilidade, e sua presença estende-se a mais regiões da República, o que significa que há mais violência no país como um todo. A população torna-se desconfiada e temerosa, e o sentimento subjetivo de insegurança acentua-se, independentemente dos índices constatados ${ }^{10}$. Na opinião dos cidadãos, a insegurança surge como o principal problema do país.

Os crimes cometidos pelo narcotráfico e pelo tráfico de armas competem à alçada federal, razão pela qual os estados não intervêm na questão. Não obstante, as organizações criminosas corrompem as polícias estaduais e municipais para que protejam suas atividades, $e$ nelas infiltram-se para anular suas estratégias. Essa situação complica ainda mais a luta, e diminui a eficiência das forças federais. As mudanças necessárias não foram aprovadas pelo Congresso, e os governadores e prefeitos opõem-se à existência de uma polícia nacional ou, ao menos, de polícias únicas em cada estado. Há acusações de que alguns governadores e prefeitos abdicaram da luta, e afirma-se que outros se aliaram aos criminosos.

Para concluir esta breve exposição, destaco três implicações do crime organizado relacionadas com aspectos econômicos, políticos e sociais. Em primeiro lugar, embora não exista uma estimativa do volume de dinheiro do crime organizado que entra e sai do país, não há dúvida de que se trata de grande quantidade e de que, se pensarmos que ao menos uma parte desse dinheiro é "lavado" no México e circula no mercado interno de bens e capitais, seu impacto na economia deve ser considerável. Pode-se aventar a hipótese de que os recursos do narcotráfico tenham possibilitado ao menos um pouco mais de dinamismo à economia mexicana. Em sentido contrário, deve-se considerar que os gastos do Estado para combater as organizações criminosas aumentaram ${ }^{11}$, e, apesar do apoio dos Estados Unidos ao Plano Mérida, tais gastos têm um impacto negativo sobre a capacidade do governo de dispor do orçamento público e atender a outras necessidades nacionais, como políticas de desenvolvimento, de infraestrutura ou gastos sociais. A luta contra o narcotráfico também afeta as instituições financeiras, pois, nas estratégias para combater a "lavagem" de dinheiro, impõem-se às instituições bancárias restrições no manejo de divisas e transações em efetivo.

Em segundo lugar, os vínculos das organizações criminosas com a política também são de vários tipos e têm diversas consequências. A mais óbvia é a corrupção exercida sobre os funcionários públicos, limitando sua autonomia. Nos anos recentes, aumentaram as suspeitas 
de que o narcotráfico financie campanhas políticas de alguns partidos ou candidatos, imponha nomes para cargos públicos eletivos, assassine candidatos que não lhes sejam favoráveis ou que estejam comprometidos com organizações rivais. Isso, sem dúvida alguma, afeta o funcionamento da democracia eleitoral. Do mesmo modo, sua intromissão e seus efeitos também são muito significativos na administração pública. É cada vez mais evidente que o crime organizado controla os presídios, de onde os "capos" detidos operam, redefinindo o funcionamento dos centros de readaptação e estendendo seu controle sobre todas as ramificações do crime representadas pelos detentos nesses locais ${ }^{12}$. Há também indícios de que controlem vários municípios nos estados em que sua presença é mais relevante.

Em terceiro lugar, no plano da sociedade, o narcotráfico criou novas realidades. O crime organizado ligou-se a certos grupos sociais, especialmente jovens que estão a seu serviço. Nas localidades onde a organização opera, tais grupos encarregam-se de garantir a segurança e de promover melhorias materiais. A existência prévia de gangues facilitou a simbiose. Entretanto, a mudança mais impressionante, $e$ talvez mais relevante, é seu impacto na cultura dos mexicanos.

No ambiente de desesperança em que vive a maioria dos jovens, as organizações criminosas oferecem empregos certamente ilegais, mas bem-remunerados, envolvendo tanto as tarefas próprias do narcotráfico ou do tráfico de armas como também atividades de "sicários" ou "soldados" das organizações no embate com cartéis rivais e com as forças oficiais. O imenso número de vítimas nesses confrontos mostra que a expectativa de vida de quem se filia é muito curta. No entanto, para eles, como se diz, "mais vale ser rei por um dia do que um coitado por toda a vida"; preferem desfrutar dos prazeres oferecidos pelo dinheiro, ainda que por um período breve, do que viver uma vida cheia de privações.

Nessa vida acelerada, os jovens envolvidos renunciam não somente a uma existência longa, mas também, segundo eles próprios, à salvação no outro mundo. Estão convencidos de que sua vida nesta terra os conduzirá ao inferno, e que ali se encontrarão novamente com seus carrascos ou torturadores, pois a luta e o ódio entre as facções não termina nesta vida ${ }^{13}$. A religiosidade dos envolvidos no narcotráfico não se esgota nos ritos e símbolos do catolicismo, pois criaram-se novos santos que são considerados seus protetores. $O$ caso mais conhecido é o de Jesús Malverde, no estado de Sinaloa, ou o da Santa Morte (embora esta tenha uma freguesia mais ampla, socialmente falando). Sua religiosidade adquire uma característica peculiar, também alternativa, com santos próprios para os "defender"14.

Junto com a experiência social do narcotráfico, desenvolveu-se uma rica cultura de canções e cantigas de "corridos", narrando sobretudo a vida dos grandes capos e sua relação com a sociedade, apresen-
[12] Está provado que, a partir dos presídios, funcionam verdadeiras indústrias de extorsão por telefone, assim como de sequestros. Recentemente, descobriu-se que, de dentro de um Centro de Readaptação Social (Cereso), era controlado um grupo de "sicários" que, à noite, saíam para executar grupos de pessoas, utilizando armas dos guardas, veículos oficiais e contando com a permissão das autoridades do presídio.

[13] Um sicário que descreve o ato de torturar um rival narra que este, apesar do sofrimento de ter a pele arrancada, profere a ameaça de que em breve se encontrarão no inferno. Ver Ruvalcaba, Héctor. "Ciudad Juárez: la vida breve". Nexos, nº 390, 2010, pp 28-35.

[14] Degetau, Jorge. "Credos: Malverde y la Santa Muerte". Este País, $\mathrm{n}^{\circ}$ 229, 2010, pp.30-33. 
[15] Pode-se mencionar, como exemplos, os romances Balas de plata, de Élmer Mendoza (México, Tusquest, 2008), ou La reina del Sur, de Arturo Pérez Reverte (México, Alfaguara, 2002).

[16] Segundo cifras oficiais, há cerca de 7 milhões de jovens nesta situação. "Investiga Procuraduría General de la República (PGR) Cereso de Gómez Palacios". El Siglo de Torreón, 24 jul. 2010.
[17] Flores, Ricardo Iglesias. "Migración: promesas pospuestas, realidades lacerantes". Este País, no 221 , 2009 , p. 18. tando-os como se fossem uma nova versão dos bandidos generosos que roubam para entregar ao povo. A música chamada "grupera", que é basicamente um corrido do norte, é um dos gêneros mais populares no país, e o que possui mais conteúdos do narcotráfico. Muitas das canções fazem apologia do narcotráfico e da violência. A cultura "narco" também tem sua expressão na literatura;o número de romances já é vasto, e alguns deles têm boa qualidade ${ }^{15}$. Em torno do narcotráfico há uma cultura dos oprimidos que se torna um canal de expressão da insatisfação da população.

Este processo cultural criou os elementos para novas identidades entre os jovens, não somente os que estão diretamente envolvidos, mas também aqueles que residem nas áreas marginalizadas, onde proliferam os chamados "ni-ni" (ou seja, "nem-nem", jovens que "nem estudam, nem trabalham" ${ }^{16}$. O que a economia legal não pode oferecer é propiciado pela atividade criminosa.

Em resumo, a violência do crime organizado tem relativa autonomia, não sendo produto da pobreza ou da desigualdade, e está muito relacionada com a dinâmica dos mercados mundiais de drogas e do contrabando. Não obstante, sua presença no país tem efeitos muito importantes em todos os âmbitos.

\section{A MIGRAÇÃO INTERNACIONAL}

Aemigração de mexicanos para os Estados Unidos é um fenômeno antigo: o fluxo existe desde a formação da nação norte-americana, no final do século XVIII, e da formação da nação mexicana, no princípio do século XIX. Este processo tornou-se visível durante a recessão de 1929 a 1932, quando os Estados Unidos deportaram mais de 250 mil mexicanos e inclusive norte-americanos de ascendência mexicana. Durante a Segunda Guerra Mundial, criou-se o programa "Braceros", que permitiu a entrada temporária de mexicanos para ocuparem-se de atividades agropecuárias e, em menor medida, fabris. O programa terminou em 1962. Mesmo durante a vigência do programa, muitos imigrantes não regressaram, permanecendo nos Estados Unidos de maneira ilegal.

A partir de então, a migração ilegal não parou de crescer,e o número de cidades ou regiões nas quais se radicam os mexicanos ilegais ampliou-se. Em 1986, promulgou-se nos Estados Unidos o Immigration Reform and Control Act, que anistiou os imigrantes ilegais; a esta lei recorreram mais de 2,3 milhões de mexicanos. Dessa data em diante, o número de imigrantes voltou a crescer, e atualmente discute-se a necessidade de realizar uma nova reforma das leis de imigração para solucionar o problema da população ilegal. Calcula-se que a população ilegal de origem mexicana chegue a 7,5 milhões de pessoas ${ }^{17}$. 
O principal motivo de migração é a falta de empregos no México e a busca do chamado "sonho americano". Contudo, o problema é mais complexo, uma vez que existem grandes comunidades de migrantes nacionais em cidades ou municípios dos Estados Unidos. Muitas comunidades e, naturalmente, famílias têm uma realidade e uma vida binacionais. O fluxo organiza-se com base nessas comunidades, e a migração também responde a interesses de reunificação familiar, de "passar para o outro lado" para estudar etc.

Fora do âmbito diplomático ou da relação bilateral com os Estados Unidos, a migração tem enorme relevância para o México. O país depende do dinheiro que os migrantes enviam a seus familiares. O montante de 77,2 bilhões de dólares ${ }^{18}$ representa a segunda maior fonte de divisas depois dos ingressos relativos ao petróleo, tendo superado os rendimentos provenientes do turismo. Ainda assim, perante a falta de dinamismo do mercado de trabalho interno, os fluxos migratórios aliviam a pressão por empregos. Embora tal pressão esteja ainda longe de resolver-se inteiramente, o número de emigrantes representa mais da metade dos empregos criados anualmente no México ${ }^{19}$.

A emigração também está associada a graves problemas sociais, especialmente no campo. A saída em massa de homens das comunidades rurais altera as estruturas familiares, sobrecarregando as mulheres no cuidado da família e também no trabalho agrícola. Essas famílias dependem das remessas para sobreviver, além dos auxílios oferecidos pelo governo por meio de diversos programas sociais. O drama daqueles que ficam costuma ser terrível.

No outro extremo da estrutura social, a emigração de pessoas com alta escolaridade cria um problema na oferta interna de profissionais, que já é baixa.

Os mexicanos ou norte-americanos de origem mexicana que vivem nos Estados Unidos pressionam constantemente para que lhes seja concedida a cidadania mexicana, pois querem ter o direito de voto e de participar da política nacional. Estão conscientes da importância de suas remessas e de seus interesses, e além disso exigem que o Estado mexicano intervenha com mais vigor na defesa de seus direitos perante as autoridades norte-americanas.

Por fim, não posso deixar de assinalar que os emigrantes, as comunidades mexicanas nos Estados Unidos, contribuem para criar novas culturas, como no caso do narcotráfico. Há a criação de uma cultura dos méxico-norte-americanos (o caso mais conhecido foi o movimento "Chicano"). É uma cultura que une e recria a realidade binacional. O fenômeno da migração está presente em nosso cotidiano.
[18] Cámara de Diputados, LXI legislatura em 〈htpp://www. Diputados. gob.mx/cedia/sia/se-1555-22-10.pdf).

[19] Em 2007, criaram-se $403 \mathrm{mil}$ empregos no setor formal; em 2008 , apenas $48 \mathrm{mil}$;em 2009 , perderam-se 771 mil, e, este ano, até o momento, criaram-se 556 mil empregos formais. Este País, op cit. 
[*] As "maquiladoras" são empresas estabelecidas em locais com mão de obra barata e facilidades tributárias, que trazem insumos (matérias-primas, componentes etc.) do exterior para fabricar mercadorias em condições mais vantajosas e, posteriormente, exportá-las [N.da T.].

\section{O CÍRCULO VICIOSO DA ECONOMIA}

A transformação da economia levou a uma péssima inserção no mercado internacional e, paralelamente, ao abandono do mercado interno, gerando um círculo vicioso.

Para compreender o processo, devemos retroceder a 1970, quando se dá a mudança na economia mundial, com a crise do Estado keynesiano e o desenvolvimento do neoliberalismo. Nos primeiros mandatos presidenciais já inseridos na crise (1970-1982), desenvolveu-se uma política voltada para o passado, baseada na maior intervenção do Estado, inspirada no modelo populista do cardenismo dos anos de 1930. O resultado desses dois sexênios foram as crises de 1976 e 1982, crises fiscais do Estado, crises do balanço de pagamentos e inflação alta. Por fim, o período de extremo nacionalismo e terceiro-mundismo terminou por deixar nas mãos do FMI as decisões centrais da economia mexicana.

A partir da crise econômica de 1982, as autoridades decidiram que a economia deveria integrar-se ao mercado mundial, privilegiando o setor manufatureiro "maquilador", especialmente o automotivo e o eletroeletrônico, ligado ao mercado norte-americano. Isto foi reforçado normativamente com o Tratado de Livre Comércio da América do Norte (Nafta), de 1994. Em conformidade com a decisão de privilegiar a via maquiladora, e em comunhão com o Consenso de Washington, destruiu-se a indústria existente (certamente ineficiente e protegida), que servia ao mercado interno, que passou a ser abastecido pelas importações.

A nova forma de integração ao mercado mundial teve consequências de enorme importância para a sociedade mexicana. A decisão de converter a indústria em indústria maquiladora para o mercado norte-americano fomentou a industrialização das cidades da fronteira com o país vizinho, como Tijuana, Mexicali, Ciudad Juárez, Nuevo Laredo, Matamoros etc., enquanto as antigas zonas industriais situadas no centro do país sofreram processos de desindustrialização, de desemprego e, sobretudo, de crescimento acelerado do setor informal do mercado de trabalho. O sul do país, sempre marcado pelo subdesenvolvimento, permaneceu igual.

As mudanças na distribuição geográfica das empresas foram acompanhadas por movimentos migratórios da população. As cidades da região norte sofreram processos de imigração de trabalhadores, que buscavam emprego nas maquiladoras, o que era reforçado pelos antigos processos de migrantes rumo aos Estados Unidos. Quando os migrantes não conseguiam cruzar para o outro lado, ou quando eram deportados, ficavam na zona fronteiriça. Diante da absoluta falta de políticas urbanas e de desenvolvimento social, as cidades tiveram um crescimento desordenado, gerando grandes áreas marginais e de miséria. 
Além disso, a política maquiladora exigia, como fator central para atrair investimentos de empresas estrangeiras, salários e impostos baixos. O modelo é incapaz de dinamizar o mercado interno; pelo contrário, tende a deprimi-lo.

As áreas rurais do país sofreram um processo similar. Algumas, com as melhores terras e a melhor infraestrutura, orientaram-se para a exportação de produtos como verduras, legumes e frutas, enquanto o restante produzia seus produtos tradicionais, como milho e feijão, em propriedades minifundiárias (de menos de cinco hectares) com taxas de produtividade muito baixas. Adependência alimentar do país aumentou. $\mathrm{O}$ abastecimento passou a depender cada vez mais das importações, especialmente de grãos, com exceção do milho branco.

Paradoxalmente, no novo modelo persistiu uma certa rigidez relativa a aspectos do modelo anterior. As grandes empresas estatais produtoras de energia, como a Pemex (petróleo) e a Comisión Federal de Electricidad (CFE) mantiveram seu monopólio e sua organização interna corporativa. Esses monopólios impõem aos consumidores custos altos e baixa qualidade de produtos e serviços.

Juntamente com os monopólios estatais, cujos sindicatos funcionam como enclaves de poder, poderes fáticos, mantiveram-se velhos monopólios privados e criaram-se novos em áreas tão suscetíveis como as televisões, em que funciona um duopólio, com predomínio da empresa Televisa, a telefonia fixa e móvel, com predomínio das empresas Telmex e Telcel, a produção de cimento, com preponderância da Cemex, a produção industrial de alimentos, como Gruma, Bimbo etc. Esses monopólios ou oligopólios, com forte presença no mercado internacional, também funcionam como poderes de fato, impõem altos custos aos consumidores e são fatores de resistência à mudança do modelo econômico.

Mais uma vez, paradoxalmente, os monopólios privados e estatais funcionam como freios para a mudança em sentido contrário. Enquanto os primeiros lutam pelo mercado, os segundos lutam pelo Estado. Nada se move!

Também no setor financeiro há mudanças importantes. O sistema bancário foi nacionalizado em 1982, e depois privatizado nos anos subsequentes, sendo por fim desnacionalizado nos últimos anos da década de 1990 e nos primeiros anos do século XXI. Atualmente, os quatro bancos mais importantes são estrangeiros e controlam mais de dois terços de todo o sistema. Até o momento, o setor não funcionou como um facilitador do crédito para impulsionar a produção interna.

Cabe destacar que, nos serviços públicos como educação e saúde, manteve-se, de um lado, a antiga estrutura corporativa, o que reproduz os velhos vícios e a falta de qualidade, e, de outro lado, privilegiou-se a participação crescente do capital privado, nacional e internacional, na educação superior, assim como na administração das aposentadorias. 
[20]A produção de Cantarell começou a cair a partir de 2004, obrigando a Pemex a explorar novas alternativas. Cantarell produziu, em 2007, 1,5 milhões de barris por dia. Ver 〈http://www.pemex.com/index〉.
A nova configuração da economia mexicana tornou-se extremamente dependente da economia dos Estados Unidos e muito sensível a suas crises, como se evidenciou com a crise do ano de 2009 , quando a economia mexicana sofreu a queda mais brutal (uma queda de 6,5\% no PIB), e também se manifesta na recuperação lenta, já que depende do crescimento do mercado norte-americano, especialmente do automotivo.

O modelo maquilador de incorporação ao mercado mundial aprofundou as desigualdades sociais e aumentou a pobreza, que o Estado tenta atenuar mediante uma política social assistencialista. A existência de uma população excluída, sem oportunidades de trabalho formal e sem perspectivas de futuro é uma base social na qual as organizações criminosas souberam penetrare que souberam utilizar. Por outrolado, a massa marginal é um campo de cultivo para o clientelismo político, de que os partidos (especialmente o PRI eo PRD) tiram proveito. Nessa realidade, a migração para os Estados Unidos é sempre uma saída.

Um modelo econômico tão deficiente só se tornou possível em virtude da existência da renda proveniente da indústria petrolífera. No final da década de 1970, entrou em produção a imensa jazida de petróleo Cantarell, que elevou a produção até 2,8 milhões de barris por dia e que é responsável por um terço dos ingressos fiscais do governo ${ }^{20}$.

\section{AS MUDANÇAS NOS SISTEMAS POLÍTICOS}

Para compreender as mudanças no sistema político é necessário, ainda que de maneira breve, mencionar algumas características do antigo regime, pois sua influência na crise atual é notória.

São quatro as características básicas do antigo regime que nos interessa ressaltar. Duas delas são muito comuns a todos os regimes do país desde que se tornou uma nação independente, e as outras são específicas do regime corporativo autoritário pós-revolucionário.

A primeira refere-se à realidade da existência de um Estado de Direito fraco, que não se cumpre na prática. As normas que articulam a ordem social e política são distintas das estabelecidas no direito formal - são sua exceção. Institucionalmente, isso se traduz numa justiça frágil e ineficaz, na impunidade dos criminosos e na indefensabilidade dos cidadãos.

A segunda característica é a existência de uma administração pública profundamente ineficiente, muito distante da ideia weberiana da racionalidade administrativa que caracteriza as burocracias modernas. A burocracia pública é corrupta, opaca e abusa constantemente do poder.

A terceira é o presidencialismo autoritário, que subordina o parlamento e o poder Judiciário, assim como os demais poderes situados nos estados e municípios. É uma ditadura institucional. 
A quarta característica é a existência de um sistema partidário estabelecido com um partido quase único. Realizavam-se eleições periódicas, respeitando-se os calendários firmados nas leis, mas cujo fim não era eleger os governantes (o escolhido em seu interior ganharia com certeza quase absoluta), e sim reproduzir ritualmente o regime. Esse sistema articulava-se com a sociedade por meio do corporativismo que controlava as bases dos trabalhadores da indústria ou dos serviços públicos e privados, dos camponeses e proprietários de terras, e também dos empresários. Nesse sistema, a luta política dava-se no interior do partido oficial, dentro do qual se expressava a pluralidade das forças políticas reconhecidas.

No final dos anos de 1960, mais especificamente a partir de 1968, o regime corporativo autoritário entrou em crise e iniciou-se o processo de mudança. As reformas limitaram-se basicamente ao âmbito eleitoral, buscando-se incluir novos setores dentro de regras mais democráticas.

A mudança política teve início timidamente, com a reforma eleitoral no governo de Echeverría (1973), chamada de abertura democrática, que se limitou a ampliar o número de deputados dos partidos (de vinte, conforme estabelecia a lei de 1964, para vinte e cinco), que conferiam à oposição tolerada acesso ao Congresso. Sem dúvida, tal reforma foi muito pequena para solucionar o descontentamento em relação ao sistema.

No governo seguinte, de José López Portillo (1976-1982), devido à crise de 1976, houve um aumento dos movimentos sociais e surgiram movimentos guerrilheiros; as forças de esquerda lutavam de fora do sistema e causavam ingovernabilidade. A reforma eleitoral de 1977 procurou incorporar os novos setores, e para isso abriu o espaço eleitoral para partidos previamente proibidos: o Partido Comunista do México (PCM), o Partido Revolucionário dos Trabalhadores (PRT), o Partido Mexicano dos Trabalhadores (PMT), de esquerda, e o Partido Sinarquista (PS), de direita. Além disso, ampliou as candidaturas plurinominais, com o que se garantiu a participação dos mesmos partidos na Câmara dos Deputados, conferindo uma nova configuração à classe política. A reforma permitiu a pluralidade e a possibilidade de alternância partidária nos poderes executivos e legislativos na federação e, nos estados e municípios, abriu novos espaços para o jogo democráti$\mathrm{co}$, mudando suas regras.

O governo, no entanto, através do PRI, mantinha o controle do processo eleitoral e tinha a última palavra sobre a legalidade e a validade dos resultados. Além disso, na Câmara dos Deputados, garantia-se a maioria absoluta para a primeira maior minoria, com a chamada "cláusula de governabilidade". Muitos autores consideram que essa reforma, apesar de suas limitações, deu início à transição rumo à democracia eleitoral. 
[21] Uma mostra dessa fragilidade foi a incapacidade do presidente Zedillo de aprovar a reforma fiscal perante a oposição no Congresso. Essa incapacidade foi uma constante até agora.
Após a fraude eleitoral que impediu que Cuauhtémoc Cárdenas, candidato de uma ampla coalizão de partidos e movimentos deesquerda, chegasse à presidência, deu-se a reforma eleitoral de 1989-1990. Com ela, o governo perdeu o controle sobre a qualificação dos resultados. Afirmou-se que os órgãos encarregados de realizar as eleições e decidir sobre sua validade haviam-se "cidadanizado", que os partidos e o governo ficavam de fora do controle e da sanção dos processos eleitorais. Logo veríamos que este não era o caso.

O presidencialismo chegou ao fim na eleição de 1997 , quando o PRI perdeu a maioria absoluta na Câmara dos Deputados e o presidente viu-se obrigado a negociar com a oposição as leis e as reformas necessárias em seu governo.

Passou-se, repentinamente, de uma presidência onipotente a um sistema presidencial com um Executivo fraco. O Legislativo e a federação ganharam poder ${ }^{21}$.

No mandato do presidente Zedillo (1994-2000), mediante uma reforma constitucional, fortaleceu-se o poder Judiciário, restabelecendo o equilíbrio de poderes no Estado. Finalmente, no ano de 2000 , deu-se a alternância no partido ganhador da eleição presidencial, quando o PAN desbancou o PRI.

Sem dúvida, esses foram avanços muito importantes no sistema político mexicano. Todavia, o autoritarismo não foi de todo eliminado, e ameaça retornar.

A democracia eleitoral no México enfrenta três problemas. $O$ primeiro é que foi conquistada tarde, quando o regime democrático já não era capaz de representar a nova sociedade, fragmentada numa realidade multicultural, especialmente no aspecto étnico, mas também em minorias diferenciadas por sua preferência sexual. O segundo diz respeito ao fato de haver, entre os atores políticos dessa democracia eleitoral, alguns que não possuem vocação e compromisso democráticos. Trata-se de um conjunto de atores (democratas e autoritários) que se agrupa num estamento gerador de enorme burocratização do processo e elevação dos custos em níveis insustentáveis para a sociedade. O terceiro problema é que a cultura política continua caracterizando-se por uma ambiguidade, qual seja, a aceitação contraditória da democracia como o melhor regime e, ao mesmo tempo, a opinião de que os líderes duros e decididos (preferência por líderes autoritários) podem representar uma possível saída para os problemas do país.

Mas, além disso, existe, no processo de mudança política, uma continuidade que ameaça o regime democrático. Refiro-me ao fato de que o PRI nunca deixou de ser o partido com o maior número de governadores, nunca deixou de controlar o maior número de cargos legislativos e de ter o maior número de prefeituras. É verdade que o partido perdeu a presidência e, em várias eleições, perdeu a 
maioria no Senado e na Câmara dos Deputados, mas se manteve como a força política mais relevante. Ainda assim, graças a seu passado corporativo e de partido único, conserva o maior aparato partidário do país e mantém o controle da maioria dos sindicatos das grandes empresas estatais e da maioria das organizações camponesas e de produtores rurais. Em virtude de sua força, foi capaz de evitar o desmantelamento de partes importantes do regime autoritário, especialmente o corporativismo. Também conseguiu anular a cidadanização das instituições encarregadas dos processos eleitorais, transformando os cidadãos representantes em quotas controladas pelos partidos. Para isso, contou com o apoio dos legisladores do PAN.

Deve-se considerar que o PRI perdeu a presidência e a maioria das câmaras para líderes carismáticos, populistas: a presidência, em 2000, para Vicente Fox, de direita, e, em 2006, para Andrés Manuel López Obrador, de esquerda.

Em eleições nas quais não intervêm fatores extraordinários (líderes carismáticos ou eventos traumáticos como o caso de Sonora ${ }^{22}$ ) é muito difícil superar o PRI, como evidenciou-se nas eleições de 2009 , quando este partido ganhou quase todos os postos executivos em disputa (alguns dos quais estavam em poder do PAN, como San Luis Potosí e Querétaro) e voltou a ter a maioria absoluta na Câmara dos Deputados. Depois dessas eleições, começou-se a falar do iminente retorno do PRI à presidência da República²3.

Nas eleições realizadas este ano, em junho de 2010, o PRI ameaçava ganhar todos os pleitos mais uma vez, mas um fenômeno novo ocorreu. O PRI não conseguiu esse feito em virtude da aliança entre o PAN, partido de direita, com os partidos de esquerda PRD, Partido Convergência e Partido do Trabalho (PT), uma aliança claramente "antipriista", realizada com o fim de "nivelar" a disputa. Com isso, esses partidos conseguiram derrotar o velho PRI em três de seus mais tradicionais redutos (Oaxaca, Sinaloa e Puebla), e estiveram muito perto de fazê-lo também em Durango e Hidalgo.

Essas eleições mudaram o significado da disputa política. De um lado, houve, ao que parece, um retorno à situação autoritária em que a meta dos partidos de oposição era remover o PRI do poder para abrir espaço para a democracia; de outro, fez-se a aliança para impedir a restauração do autoritarismo. Contudo, há uma diferença substancial; naquela época, a democratização era uma bandeira moderna e progressista que unificava a oposição, ao passo que hoje a aliança, mesmo que pretenda manter o jogo democrático, anula um de seus fatores essenciais, ou seja, a pluralidade de alternativas de governo, de projetos políticos ${ }^{24}$. Em todo caso, o prenunciado retorno do PRI diluiu-se nessa disputa democrática.
[22] Pouco antes das eleições, houve umincêndio em uma creche do IMSS, onde muitos bebês morrerram e outros sofreram queimaduras. O governador teve um péssimo desempenho e isso custou a eleição ao PRI.

[23] Obviamente, tiveram influência nas eleições a crise econômica e o aumento da violência do crime organizado, assim como os maus governos do PAN e as divisões no interior do partido; entretanto, o peso do maquinário priista foi muito evidente, e ficou claro que este partido soube canalizar o descontentamento em seu favor.

\footnotetext{
[24] Nas alianças está embutida a oposição entre o nacionalismo revolucionário da esquerda e o neoliberalismo do PAN. Na prática legislativa, o nacionalismo revolucionário uniu a esquerda com o PRI, seu verdadeiro depositário: como, por exemplo, em sua renúncia a abrir a Petróleos Mexicanos ao capital privado. Já vimos essa oposição entre os grandes monopólios públicos e privados.
} 
[25] Uma mostra do cinismo e da mediocridade da classe política foi coligida por Mauricio Merino no lamentável comentário de uma deputada: "Há pouco tempo, após uma acirrada discussão sobre os despropósitos cometidos pelo legislativo federal, uma deputada espetou-me com uma tese de sociologia política que me congelou: 'Não seengane - disse-meela nossa classe política não é senão uma amostra representativa de nossa sociedade. Isso é o que a democracia garante"'. Merino, Mauricio. "Mañana empieza el año horrible". El Universal, $31 \mathrm{dez} .2008$.
[26] Nas eleições de 2009 , deu-se um movimento espontâneo pelo voto nulo para manifestar o repúdio dos eleitores pela classe política. Alcançou $6 \%$ do total de eleitores que votaram. Para análise do significado disso, ver: "Encuesta nacional sobre el sentir ciudadano". Este País, $\mathrm{n}^{\circ} 222$, 2009, pp. 10-17.
À margem dos processos eleitorais, é importante assinalar que o domínio dos priistas permitiu-lhes configurar - ou, melhor dizendo, ampliar - aclasse política. Para isso, incorporaramos políticos dos partidos de oposição, formando uma espécie de estamento com interesses próprios.Apesar de suas óbvias diferenças ideológicas, agrupam-seem torno de uma série de interesses comuns centrados em recompensas por sua participação. Os partidos de oposição desenvolvem-se a partir da mesma cepa priista - em boa parte, ajudaram a configurar os novos partidos de esquerda: PRD, Convergência, Partido Nova Aliança (Panal).Além disso, os dissidentes internos do PRI muito frequentemente proporcionaram à oposição candidatos vencedores.

Essa classe política estruturou-se como um estamento com interesses que a diferenciam da sociedade, ecomo tal dotou-se de enormes recursos públicos para sua manutenção e reprodução, com remunerações e contribuições inacreditáveis, que o situa na elite da sociedade, representando o canal de mobilidade social mais significativo e com poder cada vez maior para decidir seu próprio futuro e o de suas organizações. As tentativas de estabelecer árbitros e tribunais independentes foram superadas por negociações e alianças que fizeram com que aqueles passassem a ser controlados pelos próprios partidos ou, até mesmo, por líderes do estamento. Na última reforma, obtiveram o monopólio da representação política, deixando à margem o restante da sociedade ${ }^{25}$.

O sistema de partidos é fechado, com três partidos competitivos (PRI, PAN e PRD) e outros quatro partidos dependentes de alianças com os primeiros para sobreviver (Convergência, PT, Panal e PV). As candidaturas independentes estão proibidas. Os partidos registrados têm o monopólio da propaganda política nos meios de comunicação de massa. As barreiras para a entrada são consideráveis; depende da vontade dos partidos atualmente existentes.

A classe política, que funciona como um estamento separado da sociedade, legislou para outorgar-se uma série de privilégios, garantiu financiamento excessivo para o funcionamento dos partidos e para a propaganda nas eleições, fixou remunerações muito altas para legisladores e funcionários que ofendem a população, concedeu regalias injustificáveis. Esses privilégios que isolam o estamento da sociedade são, ao mesmo tempo, o cimento de sua união. A disputa pelo poder do Estado é feroz, mas, apesar de tudo, procuram preservar seu estamento ${ }^{26}$.

Nas últimas eleições, ficou claro que a disputa entre as partes (os partidos) do estamento afastam-se das regras democráticas, buscando a vitória a qualquer custo. Em tais pleitos, prevaleceu a chamada guerra suja, a interferência indisfarçada por parte dos governantes, o uso do dinheiro público para apoiar seus candidatos, o clientelismo político, mostrando de maneira clara a existência de atores autoritá- 
rios, que não estão dispostos a respeitar as regras da democracia. Deve-se acrescentar a isso a ação criminosa dos cartéis, que assassinaram um candidato a governador a poucos dias da eleição e intimidaram candidatos no município para que desistissem de concorrer etc.

Esse estamento político assemelha-se à classe política que estava incrustada no interior do PRI durante o regime autoritário. Agora não existe o presidente em suas funções de árbitro, mas há uma autorregulação, difícil e conflituosa, na qual o limite dos enfrentamentos é a sobrevivência do estamento.

\section{CONCLUSÃo}

Eu dizia, no começo destas observações, que há quatro dimensões do antigo regime autoritário que devem ser consideradas para se entender a realidade mexicana. A fragilidade do Estado de Direito, uma administração pública ineficiente e corrupta, o presidencialismo onipotente e o sistema de partido único corporativo. Pois bem: os dois últimos estão superados, ao menos parcialmente - desde 1997, o presidencialismo está cada vez mais restrito, e o sistema de partido único terminou; a institucionalidade corporativa, embora conserve alguns de seus traços importantes, sobretudo em organizações sindicais e camponesas, está muito longe de ser o sistema que articulava a maioria dos setores da sociedade. É verdade que tanto o predomínio de um partido, incluindo o retorno a um regime mais autoritário, como um novo fortalecimento da instituição presidencial estão entre as possibilidades futuras; todavia, a incipiente vida democrática eleva-se como uma barreira difícil de superar.

Por outro lado, as duas primeiras dimensões continuam presentes. A despeito da reforma do poder Judiciário e do bom desempenho da Suprema Corte de Justiça, o Estado de Direito permanece muito frágil. O mesmo acontece acerca da ad ministração pública federal e, mais ainda, da estadual e da municipal. Não obstante, aqui nos deparamos com um paradoxo: a violência brutal desencadeada pelo crime organizado trouxe à luz essas profundas deficiências e está provocando a reação da população, atemorizada e decepcionada - especialmente os setores médios e altos - da sociedade civil organizada, que exige, talvez mais do que nunca, que se fortaleça o Estado de Direito, que as instituições de justiça sejam eficientes e cumpram sua função de proteger os cidadãos, garantam a segurança da população e punam os criminosos. A frase de um pai que perdeu a vida de um filho sequestrado pode resumir esse clamor: "Se no são capazes, renunciem".

A sociedade civil também espera ansiosamente por uma administração pública racional. Progrediu-se no que se refere à transparência, à prestação de contas, tanto horizontal comoverticalmente, devido à pro- 
Recebido para publicação

em 9 de agosto de 2010

\section{NOVOS ESTUDOS}

CEBRAP

88 , novembro 2010

pp. $135-151$ liferação de observatórios cidadãos de múltiplas ramificações da administração governamental.A crítica aos poderes estabelecidos é constante e aguda. A democracia, o poder do voto, o voto de castigo, por assim dizer,estão obrigando os políticos a serem mais prudentes, a abusarem menos. Terão de ser mais eficientes se quiserem manter-se no poder.

Mas continua travando o desenvolvimento do país a oposição entre uma visão nacionalista revolucionária, estatista e populista, que insiste em preservar o velho modelo resultante da revolução de 1910-1917, e a perspectiva daqueles que lutam pelo livre funcionamento do mercado, os neoliberais. Vale lembrar a presença nestes setores de atores poderosos, como, de um lado, grandes sindicatos e os partidos políticos PRI e PRD, que defendem o nacionalismo contra poderosos empresários que, de outro lado, também se constituem em poderes fáticos, o PAN e parte dos líderes do PRI.

Essa oposição está incrustada nos interesses da classe política, que privilegia a sobrevivência do estamento e dos interesses particulares em detrimento da luta democrática para definir o projeto escolhido pela sociedade.

Enquanto não for superada a inserção no mercado mundial por meio do modelo maquilador, incapaz de dinamizar o mercado interno e causador de desigualdade e miséria, no qual os velhos poderes fáticos continuam anulando os canais de mobilidade, especialmente a educação, persistirá a desesperança da população e a incapacidade de visualizar um futuro minimamente promissor.

Por fim, as dimensões da crise, a violência gerada pelo crime organizado e a migração indocumentada muito dificilmente serão superadas, ou ao menos atenuadas, enquanto os processos da economia e da política não forem adequadamente reconduzidos.

VÍctor MANuel DuRAnd PONTE é pesquisador emérito do Instituto de Pesquisas Sociais da Universidade Nacional Autônoma do México (Unam). 